DOI 10.37882/2223-2982.2021.06.04

\title{
ИННОВАЦИОННЫЕ ОБРАЗОВАТЕЛЬНЫЕ ТЕХНОЛОГИИ ПРЕПОДАВАНИЯ ИНОСТРАННЫХ ЯЗЫКОВ В УСЛОВИЯХ РЕАЛИЗАЦИИ СТАНДАРТОВ НОВОГО ПОКОЛЕНИЯ И ЦИФРОВИЗАЦИИ ОБРАЗОВАНИЯ
}

\section{INNOVATIVE EDUCATIONAL \\ TECHNOLOGIES FOR TEACHING FOREIGN LANGUAGES IN THE CONDITIONS OF IMPLEMENTATION OF NEW GENERATION STANDARDS AND DIGITALIZATION OF EDUCATION}

\section{A. Bermudes Alekina}

Summary: The article deals with the design of a modern foreign language lesson, taking into account the requirements of new generation standards and digitalization of education. The author examines in detail the main characteristics of a modern foreign language lesson, methodological approaches to its design, describes the terminological field of the problem under study. Particular attention is paid to the description of the linguo-methodological potential of some innovative educational technologies: case-study technology, tandem method and digital storytelling technology.

Keywords: educational technologies, innovative educational technologies, innovative educational technologies for teaching foreign languages, digitalization, digital educational resources.
Бермудес Алекина Алексей Эдуардович Преподаватель, Финансовый университет при Правительстве Российской Федерачии alexnaissur.work@gmail.com

Аннотация: В статье рассматриваются вопросы проектирования современного урока иностранного языка с учетом требований стандартов нового поколения и цифровизации образования. Автор подробно рассматривает основные характеристики современного урока иностранного языка, методологические подходы к его проектированию, описывает терминологическое поле исследуемой проблемы. Особое внимание в статье уделяется описанию лингвометодического потенциала некоторых инновационных образовательных технологий: кейсовой технологии (case-study), методу тандема и технологии цифрового повествования.

Ключевые слова: образовательные технологии, инновационные образовательные технологии, инновационные образовательные технологии преподавания иностранных языков, цифровизация, цифровые образовательные ресурсы.
A ктуальные тенденции современного развития системы подготовки по иностранному языку детерминированы требованиями новых Федеральных государственных образовательных стандартов, в основе которых лежит деятельностный подход. Экстраполяция его идей на обучение иностранным языкам приводит к возможности моделировать образовательный процесс с акцентом на интеракции учителя и обучающихся в разных формах - индивидуальной, парной, групповой, фронтальной (в виде пленума) [1].

На современном этапе приоритетным становится формирование у обучающихся функциональности владения иностранным языком, которая предполагает ее рассмотрение в аспекте развития функциональной грамотности школьников, а также в аспекте креативного мышления как специфического ценностно-интегративного компонента, имеющего определенное предметное содержание и нацеленного на развитие универсальных, гибких навыков («soft skills»). Реализация данных требо- ваний осуществляется в рамках классно-урочной системы в формате урока / занятия по иностранному языку, который может быть организован как оффлайн, так и онлайн. В настоящее время все чаще высказываются мнения о недостаточной эффективности такой системы, о том, что это устаревший формат, и что необходимо разрабатывать новую модель организации учебного процесса, которая в большей степени соответствовала бы дифференциации и индивидуализации, опиралась бы на учебную автономию, проектную методику и т.п. [2, c. 202-208]

Урок иностранного языка в соответствии с требованиями стандартов нового поколения является комплексным феноменом, обладающим всеми свойствами целого, то есть всего учебного процесса, ступенью на пути к достижению общих целей обучения через реализацию всех или большинства принципов обучения. Урок должен отличаться разнообразием форм, приемов обучения, строиться с использованием основных и вспо- 
могательных средств обучения. Костяк урока составляет определенным образом организованная система упражнений, то есть в каждом уроке реализуются практически все элементы методической системы.

Новые образовательные стандарты меняют не только терминологический аппарат урока иностранного языка, но и вносят существенные изменения в его содержание и структуру. Урок, соответствующий требованиям ФГОС, это целостная структурно-содержательная система, имеющая многокомпонентную структуру.

В отличие от традиционного «линейного» урока, цели урока по ФГОС определяются по четко выделенным критериям (т. е. цели урока диагностичны), основное содержание представляется как образовательная технология, имеющая мотивационную, дидактическую, организационную и другие составляющие. Планируемые результаты (предметные, метапредметные, личностные) также диагностичны, причем контроль осуществляется через критериальную оценку (взаимооценку, самооценку), которая приходит на смену суммативной оценке (отметке). Диагностируемые цели (при активном целеполагании обучающимися), соблюдение определенного алгоритма и сочетание различных видов деятельности учителя и обучающихся, которые завершаются предъявлением и оцениванием результатов, позволяют рассматривать урок как педагогический проект, и, соответственно, рассматривать проблему планирования урока или системы уроков и проблему проектирования урока [5, с. 22-33].

Проектирование современного урока иностранного языка рассматривается как создание проекта урока, соответствующего требованиям ФГОС, в том числе общедидактическим на уровне целеполагания, информационного обеспечения, организации деятельности обучающихся, используемых педагогических технологий, оценки деятельности и рефлексии.

На современном этапе обучения иностранным языкам приоритетными являются инновационные образовательные технологии, разработанные в соответствии с требованиями стандартов нового поколения и процессом цифровизации образования.

Однако несмотря на наличие четких, нормативно закрепленных требований к проектированию современного урока иностранного языка, в образовательной практике учителя сталкиваются с проблемами, в частности связанными с самим процессом проектирования, определением целей обучающей деятельности педагога, внедрением инновационных педагогических технологий и др. [3, с. 28]

Рассмотрим основные понятия, касающиеся проблематики нашего исследования.
Образовательные технологии трактуются как комплекс методов, форм и средств обучения, которые последовательно реализуются в образовательном процессе, во взаимодействии учителя/педагога и обучающихся $[6]$.

Инновационные образовательные технологии рассматриваются как такие технологии реализации образовательного процесса, которые используют инновационный потенциал современных методов, форм и средств обучения [7].

Инновационные образовательные технологии преподавания иностранных языков - это комплекс инновационных методов, форм и средств обучения иностранным языкам, который способствует развитию познавательной и творческой активности обучающихся в усвоении иностранного языка и культуры стран, говорящих на нем, а также формированию коммуникативной и межкультурной компетенций [7].

Цифровизация рассматривается как процесс перехода какого-либо производства на использование информационных технологий. В сфере преподавания иностранных языков цифровизация обозначает включение в образовательный процесс цифровых образовательных ресурсов и онлайн-технологий $[14 ; 15]$.

Цифровые образовательные ресурсы - вид образовательных ресурсов, которые интегрированы в определенный комплекс, представлены в цифровом или электронном виде и функционируют на базе информационно-коммуникационных технологий и ресурсов сети интернет [4, с. 4; 16, с. 296-298].

Система преподавания иностранных языков с включением инновационных образовательных технологий учитывает требования стандартов нового поколения, тенденций цифровизации образовательной деятельности и базируется на следующих концептуальных положениях [5, с. 22-33].

1. Современное развитие преподавания иностранных языков в разных типах образовательных организаций детерминировано тенденциями реформирования образования в целом и иноязычного образования в частности и может быть описано как непрерывное диверсификационное развитие, а конкретно по английскому языку - как глобальное. В свете новых требований ФГОС урок иностранного языка должен проектироваться с учетом современных целей, принципов, подходов к обучению иностранным языкам.

2. Основными характеристиками инновационного образовательного процесса по обучению иностранным языкам являются следующие: практическая или речевая направленность (имеется в 
виду речевая активность обучающихся: главное это не сообщение знаний, а практика общения; на уроке должна создаваться обстановка сотрудничества, сотворчества, взаимодействия между учителем и обучающимися и между самими обучающимися; задача учителя состоит в том, чтобы, управляя усвоением языкового и речевого материала, выводить учеников на владение стратегиями общения на изучаемом языке); комплексный характер (во-первых, это означает интегрированный характер овладения языковыми средствами и речевой деятельностью; во-вторых, в рамках урока взаимодействуют разные виды и формы работы, и, наконец, каждый урок является очередным шагом, продвигающим обучающихся к овладению коммуникативной компетенцией, которая сама по себе является комплексной целью, состоящий из языковой, речевой, социокультурной и др. компетенций. Кроме того, урок должен иметь развивающие и воспитательные задачи); речевая активность обучающихся (данная характеристика урока иностранного языка предполагает увеличение доли речевой активности школьников, возможно за счет взаимодействия разных видов речевой деятельности в рамках урока); опора на родной язык (необходимость использовать положительный перенос, лингвистическое и социокультурное сопоставление и сравнение); доминирующая роль отводится не сообщению знаний, а тренировке в употреблении языкового материала.

3. Основными подходами к организации преподавания иностранным языкам являются индивидуальный подход (учитель / педагог принимает во внимание индивидуальные особенности обучающихся, и с учетом этого поддерживает активность каждого отдельного ученика); smart подход (предлагаемые задания должны мотивировать учеников, быть интересными для них, учитывать индивидуальные особенности, но в то же время ориентировать их на преодоление посильных для каждого из них трудностей с тем учетом, что у учеников разные способности; то есть система заданий, используемых на уроке, должна отвечать так называемому smart принципу: она не может быть единой и неизменной для всех, должна быть гибкой, должна уметь подстраиваться под каждого ученика). Являясь методологической основой ФГОС, системно-деятельностный подход, наряду с коммуникативной направленностью, позволяет выделить признаки современного урока иностранного языка, соответствующие требованиям ФГОС: действия обучающихся на уроке должны иметь личностный смысл; при проектировании режимов работы на уроке иностранного языка учитель учитывает индивидуальность отношений в группе, коллективе обучающихся; речемыслительная активность: порождение высказывания происходит в соответствии с задачей общения; эвристичность: спонтанный, творческий характер деятельности; функциональность: содержание высказывания определяет отбор и введение единиц языка в процессе обучения; проблемный характер поставленных задач и содержания материала [8, с. 57].

4. Одним из главных требований к современному уроку является обеспечение активной самостоятельной работы учащихся, доля которой на занятии должна составлять от 60 до 70 процентов от всего времени урока. Реализовать это требование возможно практически на любом этапе занятия за счет следующих условий: активное целеполагание; активизирующие приемы, формы и методы организации работы обучающихся; интерактивные виды деятельности; дифференциация (в том числе домашнего задания); активная рефлексия. К активизирующим способам организации работы относятся, к примеру, кооперативное чтение и письмо, вихревые группы, коммуникативная салфетка, карусель, работа на станциях, диктант в движении, зигзаг-дебаты и др.

Далее рассмотрим некоторые инновационные образовательные технологии преподавания иностранных языков в условиях реализации стандартов нового поколения и цифровизации образования.

\section{Кейсовая технология}

Данная технология представляет собой стратегию обучения, которая направлена на развитие критического мышления, коммуникативных навыков и умений выстраивать взаимоотношения с партнерами в групповом общении. Она может реализовываться в рамках двух типов урока иностранного языка.

Задание центристский урок (его проектирование опирается на задание центристский подход - task based language learning), сущность которого заключается в следующем:

- обучающиеся изучают язык в процессе активизации коммуникативной деятельности, стимулом которой является задание;

- в центре внимания находится активность ученика, а задача учителя - мотивировать обучающихся с помощью соответствующих заданий к спонтанным экспериментам, творческому и гибкому использованию иностранного языка. Джейн Уиллис предложила модель занятия, в которой можно выделить две основные фазы [17]: 


\section{1 фаза - подготовительная, так называемый pre- task.}

Эффективным является прием "задом наперёд": учитель предлагает в самом начале темы фрагмент заключительного теста или контрольной работы, на основе которого ученики понимают, что им нужно узнать в рамках этой темы. Если тема уже начата, то на этом этапе могут быть предложены для прослушивания и просмотра аудио и видеозаписи аутентичных коммуникативных ситуаций. При этом учитель может предложить для анализа те части печатного аудио или видео текста, в которых используется необходимая для последующих заданий лексика, а также речевые клише, грамматические структуры.

2 фаза - основная, так называемый task cycle. Это основная фаза выполнения заданий, включает в себя следующие элементы: непосредственная работа над заданием в парах или группах; подготовка устного или письменного отчета о том, как было выполнено задание; презентация результатов перед группой. Учитель на таком уроке выполняет роль консультанта, помощника, советника, а школьники работают преимущественно самостоятельно, используя форматы парной и / или групповой работы.

Еще один тип урока - структурированный или проблемно-ориентированный урок. Он в целом соотносится с технологией проблемного обучения, опирается на обучение в сотрудничестве, активное и коммуникативное взаимодействие между учащимися и учителем, преобладающую самостоятельную деятельность учащихся. В центре внимания находится проблемная ситуация [9, с. 153-155].

Структура урока такого типа с использованием кейсовой технологии состоит из трех методических блоков:

- в первом блоке осуществляется мотивирующее начало занятия, в том числе с использованием медиа средств, ставится цель, вводится проблема, например, на основе заранее подготовленного доклада и происходит первое обсуждение, например brainstorm;

- во втором блоке осуществляется детальное обсуждение проблемы и поиск путей ее решения, анализ методов и средств, распределение обязанностей и заданий с указанием конечного продукта на выходе, например, постер или презентация, осуществляется работа с материалами, как индивидуально, так и в парах и в группах, принимается решение, формируется окончательный продукт, обсуждается в группе и происходит возврат к изначальной гипотезе и постановке проблемы. Далее обучающиеся анализируют, насколько эта гипотеза была доказана, проблема была решена, то есть осуществляется рефлексия;
- третий блок означает перенос приобретенных знаний и умений на новые ситуации. Здесь осуществляется усиленная практика в применении как на основе рабочих конспектов, так и в ходе ролевых или деловых игр. Очень важна для такого типа занятия коммуникативная составляющая, в частности так называемый управляемый учебный разговор, похожий на сократовский метод обучения, когда учитель и ученики в диалоге вместе ищут оптимальное решение.

Примеры кейсов из УМК "Spotlight" для 10 класса:

Кейс 1. Read the text and create a Mind Map!

Кейс 2. "Information gap". Each of you has a piece of text that contains important information. Information is different for everyone. But it gives the full picture of the text. Find someone who has a missing piece of text and answer the question (p. 72).

Кейс 3. "Text gap". Each of you has similar texts. But the text lacks some details. The missing details are different for everyone. Find the classmates who can fill in the gaps in your text (p. 76).

\section{Тандем-мето $\Delta$}

Данный метод рассматривается как способ организации обучения иностранному языку, при котором собеседники, владеющие разными иностранными языками (они являются для них родными), в модели парного взаимодействия общаются и таким образом обучают друг друга [1]. Главной целью тандема является формирование умений свободного общения на иностранном языке, который является для тандем-партнера родным, в ситуации реальной коммуникации, а также знакомство с иной лингвокультурой и получение страноведческой информации. Особое значение этот метод имеет для формирования межкультурной компетенции обучающихся, их учебной автономии и умений преодолевать языковой барьер. Принципиальными особенностями тандем-метода являются активное речевое взаимодействие тандем-партнеров в аутентичной ситуации с аутентичным языковым и речевым материалом; структурирование индивидуального личностно-ориентированного учебного плана в зависимости от интересов партнеров; учебная автономия, которая заключается в свободном выборе формата общения и его тематики (наиболее распространенной формой общения является свободная беседа); оценивание не процессуальной, а результативной составляющей обучения [13].

В качестве основных преимуществ данного метода исследователи и практики называют его гибкость: метод может реализовываться как самостоятельный, мо- 
жет быть интегрирован в другой курс на определенное время. Также курс может отличаться по длительности и форме коммуникации: устной, письменной, электронной [11, с. 9-13].

При обучении диалогическому общению на английском языке можно организовать цикл занятий с использованием тандем-метода следующим образом в соответствии с такими этапами:

1. Организационно-подготовительный. На этом этапе проводится практическое занятие с носителем языка по определенной тематике, усваиваются лексические и грамматические явления (for example: "Free time activities in Russia and Great Britain: new Trends).

a) What is the most popular hobby in Britain among young people?

b) What is the third top activity in the UK?

c) How do British people spend their free time?

2. Этап собственно тандема:

- формирование мобильных пар (принцип формирования пар может быть любым: простой счет 1-2, 1-2; найти половинки картинок; по интересам и т.д.);

- свободное общение в тандеме: обучающимся раздаются рабочие листы по одной и той же теме, одинаковой структуры и с одинаковыми заданиями, только на разных языках. Последовательность "обновления" рабочего языка тандема регулируется преподавателем и обычно происходит через 40 минут свободного общения. Преподаватели обоих языков исправляют ошибки во время общения партнеров по тандему.

3. Презентационный этап. На данном этапе происходит презентация результатов свободного общения обоими партнерами по тандему, сначала на одном языке, затем на другом. Тандем-партнеры сообщают, какую самую важную и интересную информацию они узнали от собеседника.

4. Контрольно-оценочный этап. Целью данного этапа является не коррекция ошибок, а оценивание работы тандема и каждого его участника отдельно.

\section{Шифровое повествование}

Эта технология предполагает реализацию цифровых технологий с целью продуцирования видео истории [10, с. 805-809]. В лингводидактике понятие "цифровое повествование" употребляется наряду с синонимичными понятиями, такими как компьютерный рассказ, цифровое эссе, электронное воспоминание, интерактивное повествование и др.

Постоянным компонентом в содержании урока или занятия с применением данной технологии является внедрение мультимедиа средств (цифровых ресурсов) аудио, видео, графики, веб-публикаций для визуализации / аудиовизуализации своего повествования [12, c. 107-113].

Методика работы по данной технологии включает несколько этапов, которые реализуются последовательно и предполагают следующие действия: 1. Продуцирование идеи. 2. Анализ выдвинутой идеи. 3. Написание сценария. 4. Раскадровка. 5. Создание аудио- или видеоматериалов. 6. Создание из частей аудио или видео цельного цифрового продукта. 7. Выгрузка цифрового продукта на онлайн-сервисы. 8. Получение обратной связи (отзывов, оценок и т.д.).

Технология цифрового повествования способствует развитию у обучающихся аудиовизуальных умений, готовности работать с цифровыми образовательными ресурсами, коммуникативной и ИКТ-компетенции, а также повышению мотивации в изучении иностранного языка за счет интересных форм работы с цифровыми эссе.

Таким образом, проектирование современного урока иностранного языка неразрывно связано с внедрением инновационных подходов, методов и технологий. Инновационные образовательные технологии преподавания иностранных языков разрабатываются и внедряются с учетом реализации стандартов нового поколения и цифровизации образования, что означает ориентацию данных технологий на комплекс методологических подходов современного иноязычного образования: коммуникативно-ориентированный, системно-деятельностный, личностно-ориентированный.

\section{ЛИТЕРАТУРА}

1. Инновационные технологии обучения иностранному языку в вузе и школе: реализация современных ФГОС: сборник научных трудов по материалам Четвертой Международной научно-практической конференции (г. Воронеж, 19-20 февраля 2019 г.): в 2 ч. / [отв. ред. М.В. Щербакова] ; Воронежский государственный университет. Воронеж: Издательский дом ВГУ. 2019. 418 с.

2. Колесников А.А. Как обучать иностранному языку студентов педагогического вуза: актуальные проблемы и возможные решения // Вестник Томского государственного университета. 2021. № 462. С. 202-208.

3. олесников А.А. Как организовать дифференцированный урок иностранного языка // Иностранные языки в школе. 2021. №1. С. 28-33.

4. Колесников А.А., Боговская И.В. Обучение иностранному языку в условиях электронной школы: анализ проблем и перспектив // Иностранные языки в 
школе. 2021. №2. С. 4-13.

5. Колесников А.А. Современный урок иностранного языка: проблемы организации и возможные решения // Иностранные языки в школе. 2017. № 11. C. 22-33.

6. Конышева А.В. Английский язык. Современные методы обучения. Минск: Тетра Системс, 2007. 352 с.

7. Коряковцева Н.Ф. Теория обучения иностранным языкам: продуктивные образовательные технологии: учебное пособие. М.: Академия, 2010.201 с.

8. Кравченко Е.В., Титова 0.К. Методы визуализации информации при обучении английскому языку // Высшее образование сегодня. 2015. № 6. С. 57-60.

9. К Краснопеева Т.О., Шевченко А.И., Гураль С.К. Проектирование индивидуальных образовательных траекторий в информационной образовательной среде // Язык и культура. 2020. № 51. С. 153-176.

10. Логинова А.В. Цифровое повествование как способ обучения коммуникации на иностранном языке // Молодой ученый. 2015. № 7 (87). С. 805-809.

11. Налётова И.В. Изменения системы образования под влиянием онлайн-технологий // Гаудеамус. 2015. № 2. С. 9-13.

12. Никулина Т.В., Стариченко Е.Б. Информатизация и цифровизация образования: понятия, технологии, управление // Педагогическое образование в России. 2018. № 8. С. 107-113.

13. Штеймарк 0.В. Повышение качества знаний студентов педагогического вуза средствами цифровых образовательных ресурсов: диссертация ... кандидата педагогических наук : 13.00.01 / Штеймарк Ольга Валентиновна; [Место защиты: Моск. гор. пед. ун-т]. Москва, 2011. 178 с.

14. Программа «Цифровая экономика Российской Федерации» / Сайт Правительства PФ. - URL: http://static.government.ru/media/ files/9gFM4FHj4PsB7915v7y LVuPgu4bvR7M0.pdf (дата обращения: 28.05.2021).

15. Цифровая образовательная среда: новые компетенции педагога: (б. материалов участников конф. Электрон.текстовые дан. (1 файл рdf: 133 с.). СПб.: Изд-во «Международные образовательные проекты», 2019. - URL : http://www.eduportal44.ru/sites/RSM0-test/SiteAssets /SitePages.pdf (дата обращения: 28.05.2021).

16. Шапиев Д.С. Цифровые образовательные ресурсы в деятельности учителя // Молодой ученый. 2019. №16. С. 296-298. URL https://moluch.ru/ archive/254/58204/ (дата обращения: 28.05.2021).

17. Willis D., Willis J. Doing Task-based Teaching. - Oxford University Press, 2007. 137 p.

\footnotetext{
(с) Бермудес Алекина Алексей Эдуардович (alexnaissur.work@gmail.com)

Журнал «Современная наука: актуальные проблемы теории и практики»
}

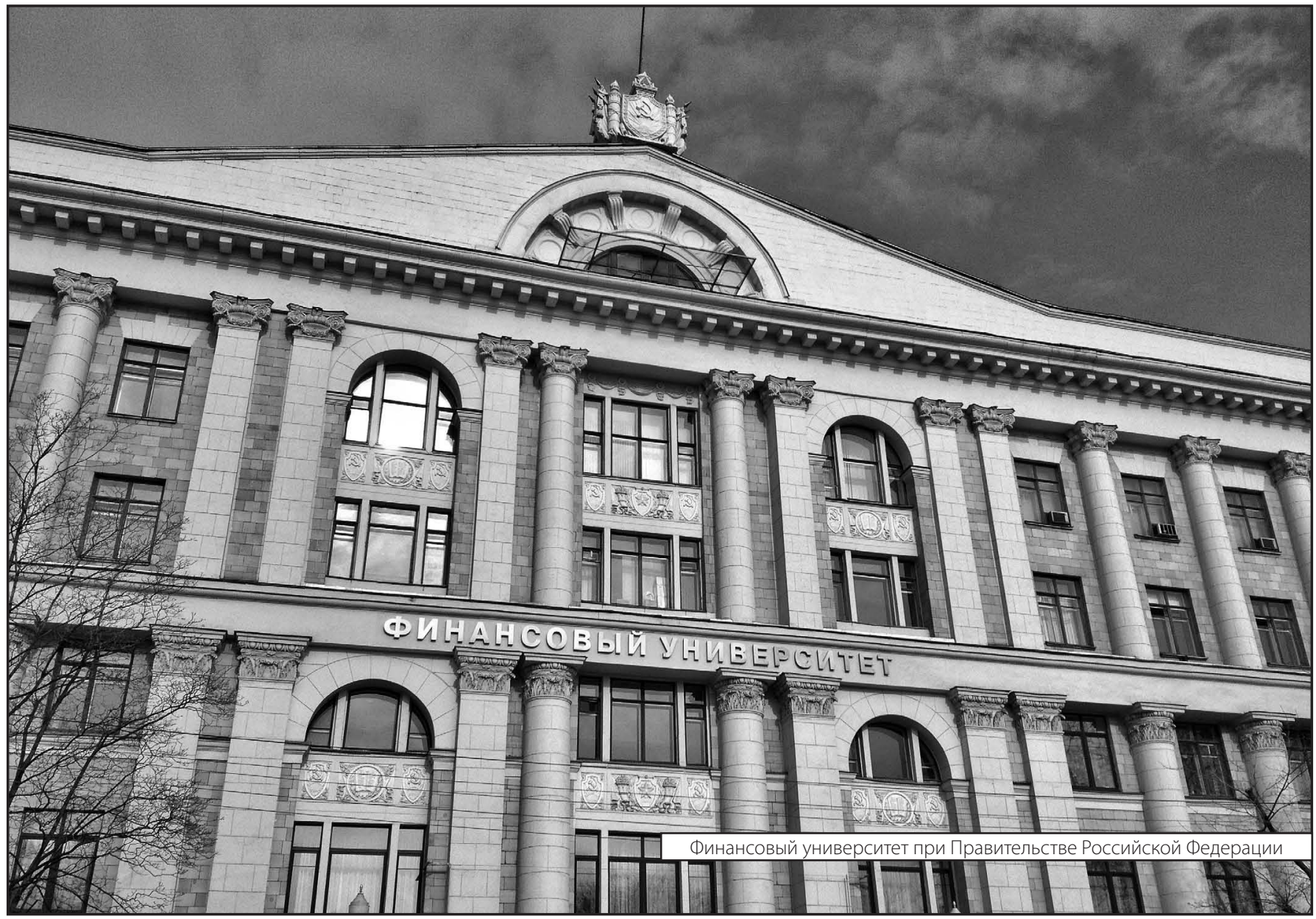

